\title{
DESEMPENHO NO CAMPO DE MUDAS DE Eucalyptus urophylla, Eucalyptus camaldulensis E Corymbia citriodora PRODUZIDAS EM DIFERENTES RECIPIENTES
}

\author{
Emerson Delano Lopes ${ }^{1}$, Cláudio Lúcio Fernandes Amaral ${ }^{2}$, Adalberto Brito de Novaes ${ }^{3}$ \\ ${ }^{1}$ Eng. Florestal, M.Sc., IFNMG, Araçuaí, MG, Brasil - emerson.lopes@ifnmg.edu.br \\ ${ }^{2}$ Biólogo, Dr., Depto. de Ciências Biológicas, UESB, Jequié, BA, Brasil - claudio.lucio@uesb.edu.br \\ ${ }^{3}$ Eng. Agrônomo, Dr., Depto. de Fitotecnia, UESB, Vitória da Conquista, BA, Brasil - adalbert@uesb.edu.br
}

Recebido para publicação: 09/04/2012 - Aceito para publicação: 05/05/2014

\begin{abstract}
Resumo
Avaliou-se a produção de mudas de Eucalyptus urophylla, E. camaldulensis e Corymbia citriodora em blocos prensados e em dois modelos de tubetes por meio da avaliação da sobrevivência e do crescimento inicial das mudas. A sobrevivência foi avaliada aos sessenta dias e o crescimento inicial em altura e diâmetro ao nível do solo ao décimo mês pós-plantio. Foi utilizado o delineamento em blocos casualizados com cinco repetições. Mudas de E. urophylla e E. camaldulensis produzidas nos blocos e nos dois modelos de tubetes e mudas de $C$. citriodora produzidas nos dois modelos de tubetes obtiveram altas taxas de sobrevivência. Já as mudas de C. citriodora produzidas nos blocos apresentaram a menor média de sobrevivência no estudo. As médias de crescimento inicial das mudas de E. urophylla produzidas nos blocos e tubetes de $50 \mathrm{~cm}^{3}$ foram superiores às encontradas para mudas produzidas em tubetes de $35 \mathrm{~cm}^{3}$. Para E. camaldulensis e C. citriodora, as médias de crescimento inicial foram semelhantes nos três recipientes. Recomenda-se a produção de mudas de E. urophylla em tubetes de $50 \mathrm{~cm}^{3}$ ou em blocos prensados. As mudas de E. camaldulensis podem ser produzidas nos três recipientes, e $C$. citriodora nos tubetes de 50 e $35 \mathrm{~cm}^{3}$.

Palavras-chave: Qualidade de mudas; desempenho pós-plantio.
\end{abstract}

\begin{abstract}
Performance in the field of Eucalyptus urophylla, Eucalyptus camaldulensis and Corymbia citriodora produced in different containers. We evaluated the production of Eucalyptus urophylla, E. camaldulensis and Corymbia citriodora in pressed blocks and two tubes models by the evaluation of survival and early growth of seedlings. We assessed survival at sixty days and initial growth in height and diameter at ground level to the tenth month after planting. We used a randomized block design with five replications. Seedlings of E. urophylla and E. camaldulensis produced in blocks, and in two tube models, and seedlings of $C$. citriodora produced in two tube models had high survival rates. On the other hand, seedlings of $C$. citriodora produced in blocks presented the lowest survival mean. The initial seedling growth mean of E. urophylla produced in blocks and tubes of $50 \mathrm{~cm}^{3}$ were higher than for seedlings grown in tubes of $35 \mathrm{~cm}^{3}$. In relation to E. camaldulensis and $C$. citriodora the average initial growth were similar in the three containers. Production of seedlings of E. urophylla is recommended in tubes of $50 \mathrm{~cm}^{3}$ or in compressed blocks, E. camaldulensis seedlings can be produced in three containers, and C. citriodora in tubes of 50 and $35 \mathrm{~cm}^{3}$.

Keywords: Seedling quality; post-planting performance.
\end{abstract}

\section{INTRODUÇÃO}

A crescente expansão do consumo de madeira e dos seus derivados conduz à busca de novas alternativas para o estabelecimento de florestas cada vez mais produtivas. A necessidade de produção de grande quantidade de mudas florestais em um curto espaço de tempo, para atender a expansão dos plantios comerciais, tem permitido a rápida evolução das técnicas de produção (FREITAS et al., 2010). Aliado a isso, se faz necessária a utilização de espécies florestais de alta produtividade, que permitam um ciclo de corte relativamente curto, associado às boas características silviculturais (SANTOS et al., 2000). 
Entre essas espécies, o Eucalyptus urophylla ST Blake, E. camaldulensis Dehn e Corymbia citriodora (Hook) Hill \& Johnson são boas opções e se destacam na produção florestal no Brasil.

Segundo Mora et al. (2000), o Eucalyptus urophylla ST Blake é nativo de algumas ilhas orientais do arquipélago de Sonda, situadas ao norte da Austrália, entre $7^{\circ}$ e $10^{\circ}$ de latitude sul. O interesse por essa espécie surgiu no Brasil nos últimos anos, após sua comprovada resistência ao cancro-do-eucalipto, sendo uma das espécies mais plantadas na região Sudeste, com a finalidade de produção de lenha, carvão, serraria e celulose. O E. camaldulensis Dehn é uma das espécies mais adequadas para as zonas críticas, onde as deficiências hídricas e problemas ligados ao solo sejam fatores limitantes para outras espécies (DEL QUIQUI et al., 2001). Segundo os mesmos autores, a espécie apresenta ampla distribuição geográfica, estando presente em quase todo o continente australiano, ocupando os mais variados ambientes ecológicos e sendo tolerante a inundações temporárias e resistente a temperaturas elevadas. A espécie Corymbia citriodora (Hook) Hill \& Johnson (ex Eucalyptus citriodora) ocorre na Austrália entre $17^{\circ}$ e $26^{\circ}$ de latitude sul, ocupando duas regiões distintas. No sul, está em altitudes não maiores do que $300 \mathrm{~m}$, e ao norte, em altitudes de 600 a 800 m (GOLFARI et al., 1978). É uma das espécies mais difundidas no Brasil, sendo plantada em todas as regiões do país. A sua madeira, de alta densidade, é excelente para serraria, carvão vegetal, lenha, dormentes, postes, estacas e mourões. Das suas folhas é extraído um óleo essencial muito utilizado na indústria química e farmacêutica (MORA et al., 2000).

O sucesso na implantação de florestas requer esforço permanente na produção de mudas com qualidade superior (OLIVEIRA et al., 2011). A ampliação das áreas de reflorestamento e a necessidade de melhorar os sistemas de produção levaram as empresas florestais a produzirem mudas em recipientes reutilizáveis, como os tubetes de plástico rígido. Segundo Santos et al. (2000), mudas produzidas em recipientes apresentam maior proteção das raízes e, dessa forma, o período de plantio poderá ser prolongado, uma vez que elas não se danificam durante o plantio, promovendo maiores índices de sobrevivência e de crescimento. Entretanto, um dos problemas observados na produção de mudas em recipientes de pequenas dimensões e de paredes rígidas são as deformações radiciais, acentuadas pelo pequeno volume de substrato que comportam (BARROSO et al., 2000).

Apesar da larga utilização de tubetes de plástico rígido no Brasil, alguns trabalhos de pesquisa apontam a utilização de blocos prensados como uma boa alternativa para a produção de mudas, tendo em vista o favorecimento ao rápido crescimento e alta sobrevivência das mudas após o plantio (BARROSO et al., 2000; LELES et al., 2000; FREITAS et al., 2010). Esse método de produção de mudas, utilizado em outros países, particularmente na Finlândia, baseia-se no uso de placas constituídas de turfa seca e prensada, fertilizadas na ocasião da sua fabricação. Novaes et al. (2002), estudando o comportamento de mudas de Pinus taeda produzidas em raiz nua, em tubetes e em blocos prensados, observou em sua avaliação que o sistema de blocos prensados foi superior aos demais métodos estudados para o desempenho das mudas no campo.

Segundo Freitas et al. (2010), as mudas produzidas no sistema de blocos prensados apresentam rápido desenvolvimento das raízes, em razão da ausência de restrição do sistema radicular e do maior espaço para crescimento quando comparado com os tubetes de plástico rígido. Leles et al. (2000) reportaram que o bloco prensado mostrou-se adequado para a produção de mudas de Eucalyptus camaldulensis Dehn, E. pellita $\mathrm{F}$. Muell e $E$. grandis Hill, verificando, ainda, que as mudas produzidas nesse sistema apresentaram altas taxas de sobrevivência no campo e maior velocidade de crescimento em altura e em diâmetro ao nível do solo, quando comparado com tubetes de plástico rígido. Freitas et al. (2006), estudando o desempenho inicial pós-plantio de mudas clonais de eucalipto produzidas em diferentes recipientes, constatou maior produção de biomassa de raiz, casca, lenho e galhos nas plantas produzidas em sistemas de blocos prensados em relação às mudas produzidas em tubetes de plástico rígido.

O trabalho teve como objetivo avaliar a produção de mudas de Eucalyptus urophylla ST Blake, E. camaldulensis Dehn e Corymbia citriodora (Hook) Hill \& Johnson em blocos prensados e em dois modelos de tubete, por meio da avaliação da sobrevivência, do crescimento inicial da parte aérea e do diâmetro ao nível do solo das mudas no campo.

\section{MATERIAL E MÉTODOS}

O presente estudo foi conduzido no município de Vitória da Conquista, na região sudoeste do estado da Bahia, em duas etapas distintas. A primeira etapa foi a produção de mudas de três espécies 
florestais em três diferentes recipientes no viveiro da Associação de Reposição Florestal do Sudoeste da Bahia (AFLORE). A segunda etapa constou da implantação das mudas, em área de fomento florestal da AFLORE, com altitude de $937 \mathrm{~m}$, localizada na latitude sul 14\%49'53" e longitude oeste $40^{\circ} 38^{\prime} 04^{\prime \prime}$.

A região onde foi implantado o experimento apresenta relevo plano, solo classificado como Latossolo Vermelho-Amarelo distrófico de textura média, temperatura média anual de $19,5{ }^{\circ} \mathrm{C}$ e precipitação média anual de $735 \mathrm{~mm}$. O clima, segundo Köppen, é classificado como tropical de altitude.

Foram testadas no experimento três espécies florestais (Eucalyptus urophylla, E. camaldulensis e Corymbia citriodora). Para as três espécies florestais, foram considerados três tratamentos, envolvendo três sistemas de produção de mudas: bloco prensado e tubete de 50 e de $35 \mathrm{~cm}^{3}$ (Figura 1).

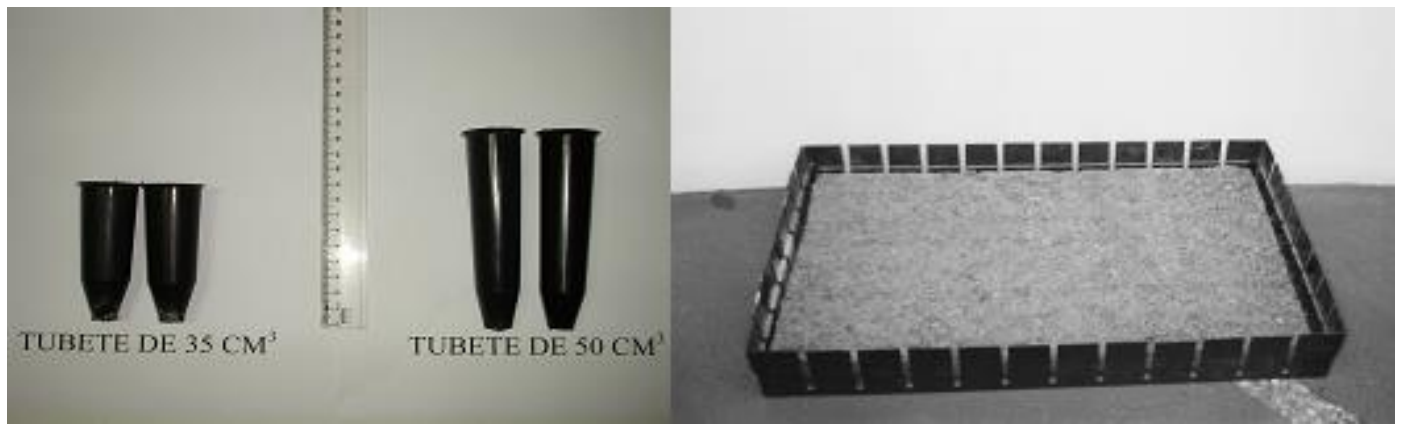

Figura 1. Tubetes de capacidade volumétrica de 35 e $50 \mathrm{~cm}^{3}$ e bloco prensado.

Figure 1. Tubes with volumetric capacity of 35 and $50 \mathrm{~cm}^{3}$ and pressed block.

Os blocos prensados utilizados para a produção de mudas foram constituídos de turfa seca prensada e adubadas na ocasião da sua fabricação. Apresentavam espessura de três $\mathrm{cm}$, expandindo para $10 \mathrm{~cm}$ quando submetidos a regas normais. Cada bloco possuía 96 orifícios de dois $\mathrm{mm}$ de profundidade, os quais foram utilizados para a semeadura, possibilitando assim a produção de 96 mudas por bloco. Os dois modelos de tubetes utilizados possuíam capacidade volumétrica de 50 e $35 \mathrm{~cm}^{3}$, com altura de 12,5 e $8,5 \mathrm{~cm}$, respectivamente. Apresentavam-se em formato cônico, com seç̧ão circular contendo quatro frisos internos equidistantes $2,8 \mathrm{~cm}$ de diâmetro na parte interna superior, e fundo aberto de aproximadamente 1 (um) $\mathrm{cm}$.

O substrato utilizado para o preenchimento dos tubetes foi um composto de casca de Pinus, turfa processada e vermiculita expandida $(5: 3: 2, \mathrm{v} / \mathrm{v})$. As características físicas do substrato constam na tabela 1. Ao substrato foi adicionado fertilizante de liberação lenta, com formulação NPK 19-06-10, aplicado como adubação de base na dosagem de $1,5 \mathrm{~kg} \cdot \mathrm{m}^{-3}$ de substrato.

Tabela 1. Características físicas do substrato utilizado na produção de mudas em tubetes.

Table 1. Physical characteristics of the substrate used in production of seedlings in tubes.

\begin{tabular}{lccc}
\hline pH & U\% & CRA \% & EC (Ms/cm) \\
\hline $5,5-6,2$ & $50-60$ & 150 & $1,8-2,5$ \\
\hline U: umidade; CRA: capacidade de retencão de água; EC: condutividade elétrica. &
\end{tabular}

A semeadura foi realizada colocando-se cerca de 5 sementes férteis nos recipientes, que receberam cobertura de uma fina camada do substrato utilizado no enchimento dos tubetes. Após o semeio, as bandejas contendo os blocos prensados e os tubetes de 50 e $35 \mathrm{~cm}^{3}$ foram dispostas em estrutura de estaleiro metálico a $0,90 \mathrm{~m}$ acima do nível do solo e, em seguida, foram cobertas com sombrite $50 \%$, para evitar ataques de pássaros e outros agentes externos. Depois de 30 dias, o sombrite foi retirado e, em seguida foi realizado o raleio das mudas excedentes, deixando-se somente a mais vigorosa e centralizada nos recipientes. Essas mudas permaneceram a pleno sol por mais 60 dias, até a sua expedição para o campo. Durante a produção das mudas, foram efetuadas 2 a 3 irrigações/dia com duração 10 min/irrigação. O viveiro contava com sistema de irrigação semiautomatizado, com aspersores com vazão de $750 \mathrm{~L} /$ hora.

Dez dias antes do plantio, ainda no viveiro, os blocos prensados foram serrados nos sentidos transversal e longitudinal visando à individualização das mudas e a regeneração das raízes podadas. 
Aos 90 dias após o semeio, foram retiradas do viveiro, aleatoriamente, as mudas das três espécies produzidas nos três recipientes, para implantação no campo e para avaliação dos seguintes parâmetros morfológicos: altura da parte aérea, diâmetro do colo e massa seca da parte aérea e do sistema radicular. As mudas utilizadas para avaliação dos parâmetros morfológicos sofreram uma lavagem cuidadosa do sistema radicular, visando a retirada do substrato aderido às raízes. Posteriormente, foi efetuada a separação da parte aérea e do sistema radicular, visando realizar as medições de altura da parte aérea e do diâmetro de colo, utilizando régua graduada e paquímetro digital, respectivamente. Para a secagem do material, foram preparadas duas embalagens de papel, uma contendo a parte aérea e outra contendo o sistema radicular, que após etiquetadas foram postas em estufa previamente aquecida a $75^{\circ} \mathrm{C}$, de acordo com as orientações de Schuurman e Goedewhagen (1971). As embalagens permaneceram abertas para facilitar a perda de umidade, e o material permaneceu na estufa por um período de $24 \mathrm{~h}$, quando atingiu peso seco constante. Após o resfriamento do material em dessecador de sílica-gel, foi realizada a pesagem por meio de balança digital, para a determinação dos pesos da massa seca.

O preparo do solo para a implantação do experimento consistiu de gradagem e abertura de covas com enxada com dimensões de $30 \times 30 \times 30 \mathrm{~cm}$. Na ocasião do plantio, foi efetuada adubação de arranque utilizando $100 \mathrm{~g}$ de superfosfato simples por cova de plantio. O espaçamento utilizado foi o de $3,0 \mathrm{~m}$ entre linhas e 3,0 m entre plantas, e o plantio foi realizado manualmente. Foram realizadas na área do experimento duas capinas manuais na linha e na entrelinha, a primeira aos dois meses e a segunda aos seis meses após o plantio.

A avaliação do desempenho das mudas no campo constou da mensuração da altura da parte aérea e do diâmetro ao nível do solo aos dez meses após o plantio, utilizando-se régua graduada e paquímetro digital, respectivamente. Para a determinação da porcentagem de sobrevivência, foram efetuadas avaliações aos 60 dias após o plantio.

O delineamento estatístico adotado foi em blocos ao acaso, com cinco repetições, sendo utilizadas 8 mudas por parcela na etapa relativa à produção de mudas e 16 mudas por parcela para a etapa de campo. Para todos os resultados obtidos, as médias foram comparadas pelo teste de Duncan ao nível de 95\% de probabilidade, e a significância dos tratamentos foi avaliada pelo teste $\mathrm{F}$.

\section{RESULTADOS E DISCUSSÃO}

Na tabela 2 encontram-se os valores médios observados de altura, diâmetro do colo, massa seca da parte aérea e massa seca do sistema radicular das mudas das três espécies florestais produzidas em blocos prensados e em tubetes de 50 e $35 \mathrm{~cm}^{3}$, retiradas do viveiro noventa dias após a semeadura.

As maiores médias de altura e de diâmetro de colo foram observadas nas mudas produzidas nos blocos prensados, nas três espécies estudadas (Tabela 2). Tal fato pode estar relacionado ao maior volume de substrato que os blocos prensados proporcionam e, consequentemente, à maior disponibilidade de nutrientes e melhor aproveitamento de água em relação aos tubetes, que, normalmente, disponibilizam um pequeno volume de substrato e promovem uma maior restrição das raízes das mudas (BOMFIM et al., 2009). As mudas de Eucalyptus urophylla produzidas nos dois modelos de tubetes não diferiram entre si para a altura, e as médias do diâmetro de colo dessa espécie foram menores nas mudas produzidas no tubete de $35 \mathrm{~cm}^{3}$. Mudas de Corymbia citriodora produzidas nos dois modelos de tubetes não diferiram entre si para o diâmetro do colo, entretanto essa espécie obteve a menor média de altura quando produzida no tubete de $35 \mathrm{~cm}^{3}$. Já para as mudas de E. camaldulensis, não foram observadas diferenças para os dois parâmetros avaliados entre os dois modelos de tubetes.

Freitas et al. (2006), estudando o comportamento de mudas de dois clones de eucalipto produzidas em blocos prensados e em tubetes, observaram, aos noventa dias após a semeadura, que as mudas nos blocos prensados apresentaram desenvolvimento em altura e diâmetro acima do esperado para plantio em campo, indicando que esse recipiente reduz o tempo de produção das mudas. Entretanto, isso não influenciou no estabelecimento das mudas em campo em relação aos tubetes.

Mudas produzidas em blocos prensados apresentaram médias superiores para massa seca da parte aérea, para as três espécies estudadas (Tabela 2), enquanto os tubetes de 50 e $35 \mathrm{~cm}^{3}$ apresentaram médias similares para esse parâmetro. Tais resultados justificam-se em função das maiores dimensões das mudas nas três espécies estudadas no sistema de blocos prensados. Nos blocos, cada muda foi produzida em aproximadamente $250 \mathrm{~cm}^{3}$ de substrato, enquanto que em tubetes de 50 e de $35 \mathrm{~cm}^{3}$, o volume foi reduzido em cinco e sete vezes, respectivamente. 
Tabela 2. Altura da parte aérea (H), diâmetro do colo (D), massa seca da parte aérea (MSPA) e massa seca do sistema radicular (MSSR) de mudas de Eucalyptus urophylla, E. camaldulensis e Corymbia citriodora, produzidas em blocos prensados e tubetes de 50 e $35 \mathrm{~cm}^{3}, 90$ dias após a semeadura.

Table 2. Height of aerial part (H), stem diameter (D), dry mass of aerial part (DMAP) and dry mass of the root system (DMRS) of Eucalyptus urophylla, E. camaldulensis and Corymbia citriodora, produced in pressed blocks and tubes with 50 and $35 \mathrm{~cm}^{3}, 90$ days after sowing.

\begin{tabular}{llllc}
\hline Recipientes & H $(\mathbf{c m})$ & D $(\mathbf{m m})$ & MSPA $(\mathbf{g})$ & MSSR $(\mathbf{g})$ \\
\hline \multicolumn{7}{c}{ Eucalyptus urophylla } \\
\hline Bloco prensado & $42,64 \mathrm{a}$ & $4,41 \mathrm{a}$ & $4,45 \mathrm{a}$ & $0,74 \mathrm{a}$ \\
Tubete de $50 \mathrm{~cm}^{3}$ & $18,23 \mathrm{~b}$ & $2,34 \mathrm{~b}$ & $0,62 \mathrm{~b}$ & $0,26 \mathrm{~b}$ \\
Tubete de $35 \mathrm{~cm}^{3}$ & $17,98 \mathrm{~b}$ & $2,07 \mathrm{c}$ & $0,61 \mathrm{~b}$ & $0,28 \mathrm{~b}$ \\
\hline \multicolumn{7}{c}{ Eucalyptus camaldulensis } \\
\hline Bloco prensado & $35,76 \mathrm{a}$ & $3,69 \mathrm{a}$ & $2,66 \mathrm{a}$ & $0,91 \mathrm{a}$ \\
Tubete de $50 \mathrm{~cm}^{3}$ & $20,43 \mathrm{~b}$ & $2,31 \mathrm{~b}$ & $0,55 \mathrm{~b}$ & $0,27 \mathrm{~b}$ \\
Tubete de $35 \mathrm{~cm}^{3}$ & $19,18 \mathrm{~b}$ & $2,07 \mathrm{~b}$ & $0,52 \mathrm{~b}$ & $0,30 \mathrm{~b}$ \\
\hline \multicolumn{7}{c}{ Corymbia citriodora } \\
\hline Bloco prensado & $20,98 \mathrm{a}$ & $2,72 \mathrm{a}$ & $1,32 \mathrm{a}$ & $0,32 \mathrm{a}$ \\
Tubete de $50 \mathrm{~cm}^{3}$ & $15,76 \mathrm{~b}$ & $2,13 \mathrm{~b}$ & $0,56 \mathrm{~b}$ & $0,32 \mathrm{a}$ \\
Tubete de $35 \mathrm{~cm}^{3}$ & $13,32 \mathrm{c}$ & $1,93 \mathrm{~b}$ & $0,48 \mathrm{~b}$ & $0,21 \mathrm{~b}$ \\
\hline
\end{tabular}

Médias seguidas pela mesma letra, na coluna, para cada parâmetro avaliado, não diferem entre si ao nível de $5 \%$ de probabilidade, pelo teste de Duncan.

Mudas de Eucalyptus camaldulensis e E. urophylla produzidas em blocos prensados apresentaram médias superiores às produzidas nos dois modelos de tubetes quanto à massa seca do sistema radicular (Tabela 2). Verificou-se, ainda, que as mudas de Eucalyptus urophylla e E. camaldulensis produzidas nos dois modelos de tubetes apresentaram massa seca das raízes semelhantes, mesmo com as diferenças da capacidade volumétrica desses recipientes. Já as mudas de Corymbia citriodora produzidas em blocos prensados apresentaram médias similares às produzidas em tubetes de $50 \mathrm{~cm}^{3}$, diferindo apenas das mudas produzidas em tubetes de $35 \mathrm{~cm}^{3}$.

$\mathrm{Na}$ tabela 3 encontram-se os valores médios observados de sobrevivência das mudas das três espécies florestais, produzidas nos três recipientes, 60 dias após o plantio no campo. As mudas de Eucalyptus urophylla produzidas em blocos prensados e nos dois tipos de tubetes obtiveram altas taxas de sobrevivência no campo, não diferindo significativamente entre si, o que evidencia que não há influência dos recipientes na produção de mudas dessa espécie quando se trata da avaliação da sobrevivência das mudas. Constatou-se para E. camaldulensis $100 \%$ de sobrevivência das mudas produzidas nos três modelos de recipientes testados. Os resultados observados para a sobrevivência dessas duas espécies foram semelhantes aos encontrados por Barroso et al. (2000) estudando o crescimento e sobrevivência de mudas de E. urophylla e E. camaldulensis produzidas em blocos prensados e tubetes.

Tabela 3. Valores médios de sobrevivência das mudas das três espécies florestais produzidas em blocos prensados e tubetes de 50 e $35 \mathrm{~cm}^{3}$, aos 60 dias após o plantio no campo.

Table 3. Medium values of survival of seedlings of the three forest species, produced in pressed blocks and tubes with 50 and $35 \mathrm{~cm}^{3}$ at 60 days after planting in the field.

\begin{tabular}{|c|c|c|c|}
\hline \multirow{2}{*}{ Espécies } & \multicolumn{3}{|c|}{ Sobrevivência (\%) } \\
\hline & Bloco prensado & Tubete de $50 \mathrm{~cm}^{3}$ & Tubete de $35 \mathrm{~cm}^{3}$ \\
\hline Eucalyptus urophylla & $97 \mathrm{a}$ & $96 \mathrm{a}$ & $93 \mathrm{a}$ \\
\hline Eucalyptus camaldulensis & $100 \mathrm{a}$ & $100 \mathrm{a}$ & $100 \mathrm{a}$ \\
\hline Corymbia citriodora & $85 \mathrm{~b}$ & $92 \mathrm{a}$ & 98 a \\
\hline
\end{tabular}

Médias seguidas pela mesma letra, na linha, não diferem entre si ao nível de 5\% de probabilidade, pelo teste de Duncan.

As mudas de Corymbia citriodora produzidas nos tubetes de 50 e $35 \mathrm{~cm}^{3}$ não diferiram significativamente entre si, apresentando altas taxas de sobrevivência (92 e 98\%, respectivamente), enquanto as mudas dessa espécie produzidas nos blocos prensados obtiveram a menor média de sobrevivência do estudo (85\%) (Tabela 3). Na individualização das mudas produzidas nos blocos, 
ocorrem podas do sistema radicular, com o objetivo de favorecer a ramificação mais intensa das raízes e, consequentemente, maior enraizamento após o plantio (FREITAS et al., 2005). Segundo Costa et al. (2011), a espécie Corymbia citriodora possui um sistema radicular frágil que não resiste à exposição ou poda. Provavelmente, os blocos prensados de $C$. citriodora, quando submetidos à individualização, não obtiveram a regeneração adequada das raízes podadas, o que pode ter afetado a qualidade e o aumento da mortalidade das mudas no campo.

$\mathrm{Na}$ tabela 4, encontram-se os valores médios observados de altura da parte aérea e diâmetro ao nível do solo das mudas das três espécies florestais, produzidas nos três recipientes, avaliadas aos dez meses após o plantio no campo.

Tabela 4. Valores médios de altura da parte aérea e diâmetro ao nível do solo de mudas das três espécies florestais produzidas em blocos prensados e em tubetes de 50 e $35 \mathrm{~cm}^{3}$, aos 10 meses após o plantio.

Table 4. Medium values of height of the aerial part and diameter at the level of the soil of plants of the three forest species, produced in pressed blocks and in tubes with 50 and $35 \mathrm{~cm}^{3}$ to the 10 months after planting.

\begin{tabular}{lcc}
\hline Recipientes & Altura da parte aérea $(\mathbf{m})$ & Diâmetro ao nível do solo $(\mathbf{c m})$ \\
\hline & Eucalyptus urophylla \\
\hline Bloco prensado & $2,97 \mathrm{a}$ & $4,65 \mathrm{a}$ \\
Tubete de $50 \mathrm{~cm}^{3}$ & $3,01 \mathrm{a}$ & $4,83 \mathrm{a}$ \\
Tubete de $35 \mathrm{~cm}^{3}$ & $2,69 \mathrm{~b}$ & $4,38 \mathrm{~b}$ \\
\hline & Eucalyptus camaldulensis \\
\hline Bloco prensado & $3,11 \mathrm{a}$ \\
Tubete de $50 \mathrm{~cm}^{3}$ & $3,05 \mathrm{a}$ & $4,02 \mathrm{a}$ \\
Tubete de $35 \mathrm{~cm}^{3}$ & $3,02 \mathrm{a}$ & $4,05 \mathrm{a}$ \\
& Corymbia citriodora \\
\hline Bloco prensado & $2,09 \mathrm{a}$ \\
Tubete de $50 \mathrm{~cm}^{3}$ & $2,15 \mathrm{a}$ & $3,91 \mathrm{a}$ \\
Tubete de $35 \mathrm{~cm}^{3}$ & $2,05 \mathrm{a}$ & $2,60 \mathrm{a}$ \\
\hline
\end{tabular}

Médias seguidas pela mesma letra, na coluna, para cada parâmetro avaliado, não diferem entre si ao nível de $5 \%$ de probabilidade, pelo teste de Duncan.

Os resultados obtidos para Eucalyptus urophylla demonstraram que as médias de altura da parte aérea e do diâmetro ao nível do solo das mudas oriundas de blocos prensados e dos tubetes de $50 \mathrm{~cm}^{3}$ foram significativamente superiores às encontradas para as mudas produzidas em tubetes de $35 \mathrm{~cm}^{3}$ (Tabela 4). Barroso et al. (2000), estudando o efeito de recipientes sobre o desempenho de mudas de Eucalyptus urophylla em condição de campo, reportaram que as deformações causadas por recipientes de paredes rígidas e de pequenas dimensões persistiram após o plantio, comprometendo o desenvolvimento inicial das mudas no campo. Moroni et al. (2003), estudando o comportamento de crescimento de diferentes espécies florestais, observaram que algumas espécies são sensíveis à restrição de crescimento do sistema radicular, sendo essa restrição provocada por recipientes de pequena dimensão, o que vem a comprometer o crescimento inicial das mudas quando plantadas em campo.

De acordo com Barroso et al. (2000), ainda que as diferenças em altura e diâmetro das mudas implantadas no campo possam diminuir ao longo do tempo, o melhor desenvolvimento inicial permite que as mudas saiam mais rapidamente da competição com as plantas daninhas, reduzindo os custos de manutenção dos plantios florestais. Para Carneiro (1995), quanto melhor o desempenho inicial das mudas no campo, nos meses subsequentes ao plantio, menor será a necessidade de tratos culturais, o que contribuirá para a redução dos custos de implantação do povoamento florestal.

As mudas de Eucalyptus camaldulensis e Corymbia citriodora produzidos nos dois modelos de tubetes e em blocos prensados apresentaram o mesmo comportamento de crescimento em altura da parte aérea e de diâmetro ao nível do solo (Tabela 4). Provavelmente, essas duas espécies são mais tolerantes a restrição e deformações radiciais provocadas pela rigidez e baixa capacidade volumétrica dos dois modelos de tubetes testados. Esses resultados evidenciam que essas duas espécies podem ser produzidas em tubetes sem o comprometimento do crescimento inicial das mudas no campo. 
Morgado et al. (2000) verificaram que mudas de Eucalyptus spp. produzidas em blocos prensados e em tubetes não apresentaram diferenças significativas de crescimento aos 12 meses após o plantio no campo. Freitas et al. (2006) observaram que as diferenças em função do sistema de produção de mudas em tubetes de $50 \mathrm{~cm}^{3}$ e em blocos prensados são reduzidas ao longo do tempo, o que pressupõe que os dois métodos de produção são adequados para a produção de mudas para certas espécies florestais.

\section{CONCLUSÕES}

- Blocos prensados e tubete de $50 \mathrm{~cm}^{3}$ foram os recipientes que proporcionaram o melhor desempenho em campo de mudas de Eucalyptus urophylla.

- Mudas de Eucalyptus camaldulensis podem ser produzidas em blocos prensados, em tubetes de 50 ou de $35 \mathrm{~cm}^{3}$.

- Recomenda-se a produção de mudas de Corymbia citriodora em tubetes de 50 ou de $35 \mathrm{~cm}^{3}$.

\section{REFERÊNCIAS}

BARROSO, D. G.; CARNEIRO, J. G. de A.; LELES, P. S. dos S.; MORGADO, I. F. Efeitos do recipiente sobre o desempenho pós-plantio de Eucalyptus camaldulensis Dehn e Eucalyptus urophylla ST Blake. Revista Árvore, Viçosa, MG, v. 24, n. 3, p. 291 - 296, 2000.

BOMFIM, A. A.; NOVAES, A. B. de; SÃO JOSÉ, A. R.; GRISI, F. A. Avaliação morfológica de mudas de madeira-nova (Pterogyne nitens Tull.) produzidas em tubetes e sacos plásticos e de seu desempenho no campo. Revista Floresta, Curitiba, PR, v. 39, n. 1, p. 33 - 40, 2009.

CARneIRO, J. G. de A. Produção e controle de qualidade de mudas florestais. Curitiba: UFPR/FUPEF, Campos, RJ: UENF, 1995. 451 p.

COSTA, F. G.; VALERI, S. V.; CRUZ, M. C. P.; GONZALES, J. L. S. Esterco bovino para o desenvolvimento inicial de mudas de quatro matrizes de Corymbia citriodora. Revista Scientia Forestalis, Piracicaba, SP, v. 39, n. 90, p. 161 - 169, 2011.

DEL QUIQUI, E. M.; MARTINS, S. S.; SHIMIZU, J. Y. Avaliação de espécies e procedências de Eucalyptus spp. para o noroeste do estado do Paraná. Acta Scintiarum, v. 23, n. 5, p. 1173 - 1177, 2001.

FREITAS, T. A. S. de; BARROSO, D. G.; CARNEIRO, J. G. de A.; PENCHEL, R. M.; LAMÔMICA, K. R.; FERREIRA, D. A. Desempenho radicular de mudas de eucalipto produzidas em diferentes recipientes e substratos. Revista Árvore, Viçosa, MG, v. 29, n. 6, p. 853 - 861, 2005.

FREITAS, T. A. S.; BARROSO, D. G.; CARNEIRO, J. G. de A.; PENCHEL, R. M.; FIGUEIREDO, F. A. M. M. de A. Mudas de eucalipto produzidas a partir de miniestacas em diferentes recipientes e substratos. Revista Árvore, Viçosa, MG, v. 30, n. 4, p. 519 - 528, 2006.

FREITAS, T. A. S. de; BARROSO, D. G.; SOUZA, L. S.; CARNEIRO, J. G. de A.; PAULINO, G. M. Produção de mudas de eucalipto com substratos para o sistema de blocos. Revista Árvore, Viçosa, MG, v. 34, n. 5, p. 761 - 770, 2010.

GOLFARI, L.; CASER, R. L.; MOURA, V. P. G. Zoneamento ecológico esquemático para reflorestamento no Brasil. $2^{\text {a }}$ Aproximação. Belo Horizonte: Centro de Pesquisa Florestal da Região do Cerrado, 1978. $66 \mathrm{p}$.

LELES, P. S. dos S.; CARNEIRO, J. G. de A.; BARROSO, D. G.; MORGADO, I. F. Qualidade de mudas de Eucalyptus spp. produzidas em blocos prensados e em tubetes. Revista Árvore, Viçosa, MG, v. 24, n. 1, p. $13-20,2000$.

MORA, A. L.; GARCIA, C. H. A cultura do eucalipto no Brasil. São Paulo: Sociedade Brasileira de Silvicultura, 2000. $112 \mathrm{p}$.

MORGADO, I. F.; CARNEIRO, J. G. de A.; LELES, P. S. dos S.; BARROSO, D. G. Nova metodologia de produção de mudas de Eucalyptus grandis W. Hill ex. Maiden utilizando resíduos prensados como substratos. Revista Árvore, Viçosa, MG, v. 24, n. 1, p. 27 - 33, 2000. 
MORONI, M. T.; NORLEDGE, D.; BEADLE, C. L. Root distribution of Eucalyptus nitens and E. globulus in irrigated and droughted soil. Forest Ecology and Management, v. 177, p. 399 - 407, 2003.

NOVAES, A. B.; CARNEIRO, J. G. de A.; BARROSO, D. G.; LELES, P. S. dos S. Avaliação do potencial de regeneração de raízes de mudas de Pinus taeda, produzidas em diferentes tipos de recipientes, e o seu desempenho no campo. Revista Árvore, Viçosa, MG, v. 26, n. 6, p. 675 - 681, 2002.

OLIVEIRA, O. A. de; CAIRO, P. A. R.; NOVAES, A. B. de. Características morfofisiológicas associadas à qualidade de mudas de Eucalyptus urophylla produzidas em diferentes substratos. Revista Árvore, Viçosa, MG, v. 35, n. 6, p. 1173 - 1180, 2011.

SANTOS, C. B.; LONGHI, S. J.; HOPPE, J. M.; MOSCOVICH, F. A. Efeito do volume de tubetes e tipos de substratos na qualidade de mudas de Cryptomeria japonica (L.F.) D. Ciência Florestal, Santa Maria, SC, v. 10, n. 2, p. 115, 2000.

SCHUURMAN, J. I.; GOEDEWAAGEN, M. A. J. Methods for the examination of root systems and roots. Wcgeningen, 2 ed. 1971. 